\title{
Pharmacotherapy for Hepatic encephalopathy: view of Evidence-Based Medicine
}

\author{
Ming-Hua Zheng ${ }^{1 *}$, Dan-Qin Sun ${ }^{1}$, Qian Jiang², Ke-Qing Shi', Ai-Min Wu and Yong-Ping Chen ${ }^{1 *}$ \\ ${ }^{1}$ Department of Infection and Liver Diseases, Liver Research Center, The First Affiliated Hospital of Wenzhou Medical College, Wenzhou 325000, China \\ ${ }^{2}$ Department of Pharmacy, the Second people's Hospital of Sichuan Province, Sichuan provincial Cancer Hospital, Chengdu 610041, China \\ ${ }^{3}$ Information Service Department, Library of Wenzhou Medical College, Wenzhou 325000, China
}

\section{Summary}

Hepatic encephalopathy (HE) refers to a complex and reversible neuro-psychiatric syndrome that results from complications of acute or chronic hepatic failure, particularly alcoholic cirrhosis. It will lead to frequent life disruptions, poor quality of life and extensive use of health care resources. We conducted the review of several agents based on randomized controlled trials (RCTs) of high-quality Jadad scores $(\geq 3)$ to provide effective information for clinical practice. Rifaximin appears at least to be as effective as conventional treatments, but not superior to them. L-Ornithine-L-aspartate appears to be a safe and effective treatment of chronic HE when compared with a placebo regime. Other treatments include non-absorbable disaccharides (NAD) and benzodiazepine receptor antagonists. In spite of the variability in the improvement of HE, NAD and non-absorbed antibiotics such as rifaximin offer a favorable benefit-risk ratio in the improvement of HE. Further RCTs with power calculation and a multi-centre approach with adequate population number are needed to resolve the heterogeneous results

Keywords: Hepatic encephalopathy; Randomized controlled trial; L-Ornithine-L-aspartate; Rifaximin

\section{Introduction}

Hepatic encephalopathy (HE) refers to a complex and reversible neuro-psychiatric syndrome that result from complications of acute or chronic hepatic failure, particularly alcoholic cirrhosis [1,2]. Clinical manifestations of $\mathrm{HE}$ can vary widely from minor signs of altered brain function, overt psychiatric, and/or neurological symptoms to deep coma, which will lead to frequent life disruptions, poor quality of life and extensive use of health care resources. It is also an independent risk factor for death [3].

The accumulation of unmetabolized toxins (primarily ammonia) in the brain, false neurotransmitters and neuro-inhibitory substances are believed to be the main mechanisms of HE. Precipitating factors include gastrointestinal bleeding, infections or systemic inflammatory response syndrome, renal and electrolyte disturbances, dehydration, use of psychoactive medications, constipation, excess dietary protein, and acute deterioration of liver function. Therefore, current management of HE focuses on exclusion of other causes of encephalopathy, identification of precipitating factors, resolution of the accumulation of neurotoxic byproducts of protein metabolism (measured by ammonia level) and correction of electrolyte balance [1-3].

The most commonly used therapies for treatment and prevention are non-absorbable disaccharides (NAD), in spite of limited studies evaluating the safety and efficacy, which calls for new therapeutics worldwide. Therefore, we conducted the review of several agents, e.g. rifaximin, L-Ornithine-L-aspartate (LOLA) based on randomized controlled trials (RCTs) of high-quality Jadad scores $(\geq 3)$, which assessed the degree of randomization, blinding, subject withdrawals and dropouts, to provide effective information for clinical practice.

\section{Rifaxinmin}

Background: Rifaximin, a derivative of rifamycin, has a very low rate of systemic absorption $(<0.4 \%)$ after oral administration, acts by inhibiting a spectrum of antibacterial ribonuclease acid synthesis. The drug was first introduced in Italy in 1987, and was used as first line therapy for hepatic encephalopathy in Europe, Asia, and Africa. In the United States, however, it was used for the treatment of non-dysenteric diarrhea, but not for HE [2]. During the past decade, numeric studies have identified that rifaximin was at least as safe and as effective as lactulose and other non-absorbable antibiotics, such as neomycin and paromomycin, for the treatment of HE [4-11].

Clinical efficacy of rifaximin: Clinical efficacy was defined as improvement of clinical syndrome, mental state and EEG and significant decrease of ammonia level. A total of five RCTs were registered in our study. The quality scores were listed in Table 1. All the included trials were of high quality. In these studies, two compared rifaximin with lactitol, three with lactulose, one with neomycin and the rest one with placebo (Table 1). The main features of these trials included are shown in Table 2.

In 1993, a randomized, double-blind, double-dummy, controlled trial was designed to compare rifaximin and lactulose for the treatment of patients with stage 1 porto-systemic encephalopathy (PSE) for 3 months. Mental status, ammonia level, asterixis and PSE severity were all improved. However, it concluded that clinical efficacy of rifaximin

*Corresponding authors: Ming-Hua Zheng, Department of Infection and Liver Diseases, Liver Research Center, The First Affiliated Hospital of Wenzhou Medical College, No.2 Fuxue lane, Wenzhou, Zhejiang, China, Tel: (86) 577-88078232; Fax: (86) 577-88078262; E-mail: blueman1320@163.com

Yong-Ping Chen, Department of Infection and Liver Diseases, Liver Research Center, The First Affiliated Hospital of Wenzhou Medical College, No.2 Fuxue lane, Wenzhou, Zhejiang, China, Tel: (86) 577-88078232; Fax: (86) 577-88078262; E-mail: ypchen77@hotmail.com

Received October 20, 2011; Accepted December 15, 2011; Published December 18, 2011

Citation: Zheng MH, Sun DQ, Jiang Q, Shi KQ, Wu AM, et al. (2011) Pharmacotherapy for Hepatic encephalopathy: view of Evidence-Based Medicine. J Liver 1:102. doi:10.4172/2167-0889.1000102

Copyright: (c) 2011 Zheng MH, et al. This is an open-access article distributed under the terms of the Creative Commons Attribution License, which permits unrestricted use, distribution, and reproduction in any medium, provided the original author and source are credited. 
Citation: Zheng MH, Sun DQ, Jiang Q, Shi KQ, Wu AM, et al. (2011) Pharmacotherapy for Hepatic encephalopathy: view of Evidence-Based Medicine. J Liver 1:102. doi:10.4172/2167-0889.1000102

Page 2 of 5

was not superior to lactulose. In an open-label prospective randomized trial conducted in Korea [9], the efficacy and safety of rifaximin was reported to be no better than lactulose (the HE index; rifaximin group $(10.0-->4.2, \mathrm{p}=0.000)$; lactulose group (11.3 --> 5.0, $\mathrm{p}=0.000)$. Mas et al. [8] conducted a randomized, double-blind, double-dummy controlled study of rifaximin $1,200 \mathrm{mg} /$ day $(\mathrm{n}=50)$ and lactitol $60 \mathrm{~g} /$ day $(n=53)$ in patients with grade I-III and acute HE for 5-6 days. HE index mental status, asterixis, EEG and ammonia level were evaluated. The results had showed that PSE was decreased to some extent, due to a greater efficacy of blood ammino and EEG abnormalities. The total effectiveness was similar: $81.6 \%$ in the rifaximin group and $80.4 \%$ in the lactitol group, respectively. It suggested that rifaximin might be a good alternative for patients with acute $\mathrm{HE}$ of moderate to severe grade. Another high-quality controlled trial reported that rifaximin was not superior to lactitol [6]. Recently, Nathan $M$ et al. [12] performed a RCT comparing rifaximin $(\mathrm{n}=140,550 \mathrm{mg}$, bid for 6 months) with placebo $(n=159)$ in 299 patients. $87.9 \%$ of patients in the rifaximin group were in remission from recurrent $\mathrm{HE}$ resulting from chronic liver disease as compared with $54.1 \%$ of patients in the placebo group. The significant benefits for rifaximin were evident and also significantly reduced the risk of hospitalization from $\mathrm{HE}$ over a 6-month period.
There were several studies comparing rifaximin with neomycin and other antibiotics. Migllo et al.[13] designed a double-blind, randomized trial with 60 patients in grade 1-2 score at the dose of $1 \mathrm{~g}$ three times daily.. This study indicated that rifaximin, was more effective than neomycin, although the difference was not significant. However, some oral antibiotics are not widespread due to adverse events profiles in the clinical studies.

Even though these studies reported conflicting results, our metaanalysis of rifaximin versus non-absorbale disaccharides in HE [14] concluded that there were no difference between the two regimes.

Adverse events: Rifaximin also has revealed adverse events (AEs), which were mainly gastrointestinal or systemic in nature. Paik et al [9] reported that one patient treated with rifaximin complained of abdominal pain. It was easily managed by the physician. No serious events related to rifaximin were reported in this trial. Abdominal pain and diarrhea were also reported in the other two studies and no significant difference was observed when compared with NAD. The incidence of AEs published by Nathan was flatulence (14.3\%), diarrhea (10.7\%), nausea (14.3\%), abdominal pain (8.6\%), dyspepsia

\begin{tabular}{|c|c|c|c|c|c|}
\hline First author (Year) & Control group & Randomization & Blinding & Withdraws and dropouts & Jadad score \\
\hline Mas (2003)[8] & Lactitol & $\begin{array}{l}\text { Randomization number generated by serial sealed, opaque } \\
\text { envelopes }\end{array}$ & adequately & Clearly reported & 5 \\
\hline Loguercio(2003)[6] & Lactitol & Randomization mentioned but method not specified & adequately & Clearly reported & 4 \\
\hline Massa(1993)[11] & Lactulose & Randomization number table & adequately & NR & 4 \\
\hline Giacomo(1993)[10] & Lactulose & Randomization mentioned but method not specified & adequately & NR & 3 \\
\hline Paik(2005)[9] & Lactulose & Randomization number generated by computer & NR & Clearly reported & 3 \\
\hline Migllo(1997)[13] & Neomycin & Randomization number generated by computer & adequately & NR & 4 \\
\hline Nathan(2010)[12] & Placebo & Randomization mentioned but method not specified & NR & Clearly reported & 3 \\
\hline
\end{tabular}

NR: no reported

Table 1 Jadad quality score of randomized controlled trials included in rifaximin study.

\begin{tabular}{|c|c|c|c|c|c|}
\hline First author (year) & $\begin{array}{l}\text { Study medication } \\
\text { Daily dosage } \\
\text { Duration of the treatment }\end{array}$ & No. & Type of HE & Evaluation Criteria & Conclusion \\
\hline $\operatorname{Mas}(2003)[8]$ & $\begin{array}{l}\text { Rifaximin v.s. Lactitol } \\
1.2 \mathrm{~g} / \text { day v.s. } 60 \mathrm{~g} / \text { day } \\
5-10 \text { days }\end{array}$ & 103 & Grade I-II + acute & $\mathrm{HE}$ index, mental status, asterixis, $\mathrm{EEG}, \mathrm{NH}_{3}, \mathrm{NCT}$, & $\approx$ \\
\hline Loguercio(2003)[6] & $\begin{array}{l}\text { Rifaximin v.s. Lactitol } \\
1.2 \mathrm{~g} / \text { day v.s. } 60 \mathrm{~g} / \text { day } \\
15 \text { consecutive days } / \mathrm{m} \times 3 \mathrm{~m}\end{array}$ & 22 & Grade I-II + chronic & Mental status, asterixis, $\mathrm{NH}_{3}, \mathrm{NCT}$ & $\leq$ \\
\hline Massa(1993)[11] & $\begin{array}{l}\text { Rifaximin v.s. Lactulose } \\
1.2 \mathrm{~g} / \text { day } v . s 60 \mathrm{~g} / \text { day } \\
15 \text { days }\end{array}$ & 40 & Grade II-III + chronic & Mental status, 'A' cancellation test Reitan test, EEG, HE severity & $\geq$ \\
\hline Giacomo(1993)[10] & $\begin{array}{l}\text { Rifaximin v.s. Lactulose } \\
1.2 \text { g/day v.s. } 120 \mathrm{ml} / \text { day } \\
90 \text { days }\end{array}$ & 40 & Stage1 PSE + chronic & $\begin{array}{l}\text { Mental status, asterixis, cancellation test, Reitan test, EEG, } \\
\mathrm{NH}_{3} \text {, PSE severity }\end{array}$ & $\leq$ \\
\hline Paik(2005)[9] & $\begin{array}{l}\text { Rifaximin v.s. Lactulose } \\
1.2 \mathrm{~g} / \text { day v.s. } 90 \mathrm{ml} / \text { day } \\
\text { 7days }\end{array}$ & 54 & Grade I-II + acute & $\mathrm{HE}$ index, mental status, asterixis, $\mathrm{NH}_{3}, \mathrm{NCT}$ & $\approx$ \\
\hline Migllo(1997)[13] & $\begin{array}{l}\text { Rifaximin v.s. Neomycin } \\
1.2 \mathrm{~g} / \text { day v.s. } 3 \mathrm{~g} / \text { day } \\
2 \text { weeks } / \mathrm{m} \times 6 \mathrm{~m}\end{array}$ & 60 & Grade I-II & Neuropsychiatric signs, asterixis, $\mathrm{NH}_{3}$ & $\approx$ \\
\hline Nathan(2010)[12] & $\begin{array}{l}\text { Rifaximin v.s. Placebo } \\
1.1 \mathrm{~g} / \text { day v.s. } 1.1 \mathrm{~g} / \text { day } \\
6 \text { months }\end{array}$ & 299 & Conn score $\geq 2+$ chronic & The Corn score, arterixis grade & $>$ \\
\hline
\end{tabular}

HE: hepatic encephalopathy, NCT: number connecting test; PSE:portosystemic encephalopathy, EEG: electroencephalogram 
Citation: Zheng MH, Sun DQ, Jiang Q, Shi KQ, Wu AM, et al. (2011) Pharmacotherapy for Hepatic encephalopathy: view of Evidence-Based Medicine. J Liver 1:102. doi:10.4172/2167-0889.1000102

Page 3 of 5

(6.4\%), ascites (11.4\%). Meanwhile, some serious events such as anemia, ascites, esophageal various, pneumonia were also reported in this study. However, all these studies estimated patients treated with rifaximin were more tolerant than those with NAD $[8-9,15]$.

\section{LOLA}

Background: LOLA is a stable salt which is composed of the two amino acids L-Ornithine and L-Aspartate. The use of ornithineaspartate provides substrates for the urea cycle (ornithine) and for the synthesis of glutamine (aspartate, by the transamination to glutamate), while also diminishing ammonium levels. A number of preliminary uncontrolled trials with LOLA had been carried out since 1970s, but there was no clear assessment. However, over the past 10 years, several randomized controlled trials have been conducted $[1,2,16]$.

Clinical efficacy of LOLA: Six high-quality trials were enrolled and characteristics were showed in Table 3. One involving 20 patients compared LOLA with lactulose and the other five compared with placebo (Table 4). LOLA is available both in oral or intravenous forms, and the recommended maximal intravenous infusion dose was $5 \mathrm{~g} / \mathrm{h}$. Kircheis et al. [17] reported 126 patients with minimal or manifest lowgrade HE, who were randomized to LOLA group ( $20 \mathrm{~g} /$ day infused for over $4 \mathrm{~h}$ ) or placebo group for 7 days. According to the study, LOLA resulted in significant improvement of mental state grade and portalsystemic encephalopathy index (PSEI) compared with placebo (59\% vs.
$32 \%$, respectively; $\mathrm{p}<0.001)$. Recently, an increasing number of studies were published. In 2006, a randomized lactulose-controlled study with 20 patients of chronic liver disease $(3 \mathrm{~g} /$ three times daily for 2 weeks ) indicated that there was no significant prominently difference [16] In 2010, Schmid et al. [18] performed a double-blind, randomized, placebo-controlled trial which evaluated the effect of LOLA in cirrhotic. It reported LOLA might be superior to placebo and improved Posturography (equilibrium score (ES)) and PSE Syndrome Test (PSE) (ES: 5.3\%; PSE: 1.9 vs ES: 3.9\%; PSE: 1.3, respectively). A double-blind, randomized, placebo-controlled study was designed by Acharya S.K et al. [19] in order to assess the effectiveness of LOLA in acute liver failure. However, LOLA did not improve clinical symptom, reduce the mortality(mortality: $33.3 \%$ in placebo and $42.4 \%$ in LOLA) or decrease more ammonia level than placebo $(\mathrm{P}=492)$. Based on these highquality studies, our meta-analysis showed that LOLA could markedly improve patients with mild to moderate HE [20].

Adverse events: Safety was also evaluated as important as efficacy and only a few adverse events such as abdominal pain, nausea and flatulence were frequently reported in these studies [16-18,20-22]. There were no serious adverse events related to LOLA and medications were well tolerated.

\section{NADs}

NADs, such as lactulose, were used as first-line therapies in 1966

\begin{tabular}{|c|c|c|c|c|c|}
\hline First author (Year) & Control group & Randomization & Blinding & Withdraws and dropouts & Jadad score \\
\hline Poo(2006)[16] & Lactulose & randomization table & NR & Clearly reported & 3 \\
\hline Kircheis(1997)[17] & Placebo & Computer- generated randomization number & adequately & Clearly reported & 5 \\
\hline Stauch(1998)[22] & Placebo & randomization number generator in blocks of 4 & adequately & Clearly reported & 5 \\
\hline Ahmad(2008)[21] & Placebo & Computer-generated randomization number & NR & Clearly reported & 4 \\
\hline Schmid(2010)[18] & Placebo & Computer- generated randomization number & adequately & Clearly reported & 5 \\
\hline Acharya(2009)[19] & Placebo & Computer- generated randomization number & adequately & Clearly reported & 5 \\
\hline
\end{tabular}

LOLA: L-Ornithine-L-aspartate, NR: no reported

Table 3: Jadad quality score of randomized controlled trials included in LOLA study.

\begin{tabular}{|c|c|c|c|c|c|}
\hline First author (year) & $\begin{array}{l}\text { Study medication } \\
\text { Daily dosage } \\
\text { Duration (administration) }\end{array}$ & No. & Type of HE & Evaluation Criteria & conclusion \\
\hline Poo(2006)[16] & $\begin{array}{l}\text { LOLA vs Lactulose } \\
3 \mathrm{~g} \text { tid vs } 10 \mathrm{ml} \text { tid } \\
2 \text { weeks (orally) }\end{array}$ & 20 & chronic & $\begin{array}{l}\text { Mental state, NCT time, asterixis, fasting } \mathrm{NH}_{3}, \mathrm{ECG}, \mathrm{PSE} \text {, bowel movements and } \\
\text { adverse events, quality of life assessment. }\end{array}$ & $=$ \\
\hline Kircheis(1997)[17] & $\begin{array}{l}\text { LOLA vs Placebo } \\
20 \mathrm{~g} / \text { day } \\
7 \text { days(infusion) }\end{array}$ & 126 & chronic & $\begin{array}{l}\text { Postprandial } \mathrm{NH}_{3}, \mathrm{NCT} \text { time, mental state grades, PSE, safety parameters, and } \\
\text { adverse events }\end{array}$ & $>$ \\
\hline Stauch(1998)[22] & $\begin{array}{l}\text { LOLA vs Placebo } \\
6 \mathrm{~g} \text { tid vs } 5 \mathrm{~g} \text { tid } \\
2 \text { weeks (orally) }\end{array}$ & 66 & chronic & $\begin{array}{l}\text { Postprandial } \mathrm{NH}_{3}, \mathrm{NCT} \text { time, mental state grades, PSE, liver blood tests } \\
\text { tolerance and adverse events }\end{array}$ & $>$ \\
\hline Ahmad(2008)[21] & $\begin{array}{l}\text { LOLA vs Placebo } \\
20 \mathrm{~g} / \text { day } \\
5 \text { days (infusion) }\end{array}$ & 80 & chronic & Postprandial $\mathrm{NH}_{3}$ and mental state grade & $>$ \\
\hline Schmid(2010)[18] & $\begin{array}{l}\text { LOLA vs Placebo } \\
20 \mathrm{~g} / \text { day } \\
8 \text { days (infusion) }\end{array}$ & 40 & chronic & PSE test, peripherd blood and $\mathrm{NH}_{3}$ & $>$ \\
\hline Acharya(2009)[19] & $\begin{array}{l}\text { LOLA vs Placebo } \\
30 \mathrm{~g} / \text { day } \\
3 \text { days (infusion) }\end{array}$ & 201 & actute & $\begin{array}{l}\mathrm{NH}_{3} \text {, adverse events, etiologic evaluation, serum electrolytes, blood urea, serum } \\
\text { creatinine, and arterial blood gases }\end{array}$ & $=$ \\
\hline
\end{tabular}

LOLA: L-Ornithine-L-aspartate, tid: 3 times daily, NCT: number connecting test; PSE:portosystemic encephalopathy, EEG: electroencephalogram

Table 4: Controlled clinical trials of LOLA in the treatment of HE. 
and lactitol in 1980 which aimed to reduce intestinal derived production and absorption of ammonia and enhance its elimination [23]

Published studies reported the efficacy were finite for the improvement of HE. A systematic review of 22 RCTs identified that there was insufficient evidence to support or refute the use of NADs for HE and NADs were always served as the comparator in randomized trials on HE [24]. Recently, one trial had been reported that lactulose improved both cognitive function and health-related quality of life in patients with minimal HE [25]. However, no further studies were published.

\section{Flumazenil}

From a pathogenetic point of view, it is widely accepted that the cause of HE involved gamma-aminobutyric acid (GABA). GABA and benzodiazepine could make GABA-A receptor complex tick rapidly. Therefore, flumazenil a competitive benzodiazepine antagonist has high affinity with inhibition of GABA receptor binding sites [26-28].

A meta-analysis showed that flumazenil was more preponderant in clinical and ECG improvement of HE than placebo in patients with cirrhosis [29]. In addition, another meta-analysis of 13 randomized trials with 805 patients manifested that fulmazenil had an important effect on improvement of $\mathrm{HE}$ at the end of treatment (RD 0.28 ; $95 \% \mathrm{CI}$ 0.20 to 0.37 , eight trials). However, flumazenil had no significant effect on recovery (RD 0.13 ; $95 \%$ CI -0.09 to 0.36 , two trials) or mortality (RD $0.01 ; 95 \%$ CI -0.05 to $0.07,10$ trials). It was associated with adverse events, but results were heterogeneous [26]. In summary, flumazenil may benefit patients with $\mathrm{HE}$ a lot. However, present studies do not recommend flumazenil routinely. Further studies on large patients are necessary to provide abundant evidence to the effectiveness of flumazenil.

\section{Conclusion}

Although there is variability in the improvement of HE, NADs and non-absorbed antibiotics, such as rifaximin, offer a favorable benefitrisk ratio in the improvement of HE. But, they should be recommended carefully in practice. We have entered an exciting phase in the research of HE and further RCTs with power calculation and a multi-centre approach with adequate population number are needed to resolve the heterogeneous results now.

\section{Financial Support}

This work was supported by grants from the Scientific Research Foundation of Wenzhou, Zhejiang Province, China (H20090014, Y20090269), Health Bureau of Zhejiang Province (2010KYB070), Research Foundation of Education Bureau of Zhejiang Province (Y201009942) and Project of New Century 551 Talent Nurturing in Wenzhou

\section{References}

1. Phongsamran PV, Kim JW, CupoAbbott J, RosenblattA(2010)Pharmacotherapy for hepatic encephalopathy. Drugs 70: 1131-1148.

2. Morgan MY, Blei A, Grungreiff K, Jalan R, Kircheis G, et al. (2007) The treatment of hepatic encephalopathy. Metab Brain Dis 22: 389-405.

3. Riggio O, Ridola L (2009) Emerging drugs for hepatic encephalopathy. Expert Opin Emerg Drugs 14: 537-549.

4. Di Piazza S, Gabriella Filippazzo M, Valenza LM, Morello S, Pastore L, et al. (1991) Rifaximine versus neomycin in the treatment of portosystemic encephalopathy. Ital J Gastroenterol 23: 403-407.

5. Leevy CB, Phillips JA (2007) Hospitalizations during the use of rifaximin versus lactulose for the treatment of hepatic encephalopathy. Dig Dis Sci 52: 737-741.
6. Loguercio C, Federico A, De Girolamo V, Ferrieri A, Del Vecchio Blanco C (2003) Cyclic treatment of chronic hepatic encephalopathy with rifaximin Results of a double-blind clinical study. Minerva Gastroenterol Dietol 49: 53-62.

7. Maclayton DO, Eaton-Maxwell A (2009) Rifaximin for treatment of hepatic encephalopathy. Ann Pharmacother 43: 77-84.

8. Mas A, Rodes J, Sunyer L, Rodrigo L, Planas R, et al. (2003) Comparison of rifaximin and lactitol in the treatment of acute hepatic encephalopathy: results of a randomized, double-blind, double-dummy, controlled clinical trial. J Hepato 38: 51-58.

9. Paik YH, Lee KS, Han KH, Song KH, Kim MH, et al. (2005) Comparison of rifaximin and lactulose for the treatment of hepatic encephalopathy: a prospective randomized study. Yonsei Med J 46: 399-407.

10. Giacomo F FA, Michele N, Oronzo S, Antonella F (1993) Rifaximin in the treatment of hepatic encephalopathy. Eur J Clin Res 4: 57-66.

11. Massa P, Vallerino E, Dodero M (1993) Treatment of hepatic encephalopathy with rifaximin: double blind, double dummy study versus lactulose. Eur J Clin Res 4: 7-18.

12. Nathan MB, Kevin DM, Arun S, Fred P, Guy N, et al.. (2010) Rifaximin Treatment in Hepatic Encephalopathy. N Engl J Med 362: 1071-1081.

13. Miglio F, Valpiani D, Rossellini SR, Ferrieri A (1997) Rifaximin, a nonabsorbable rifamycin, for the treatment of hepatic encephalopathy.A doubleblind, randomised trial. Curr Med Res Opin 13: 593-601.

14. Jiang Q, Jiang $X H$, Zheng $M H$, Jiang LM, Chen YP, et al. (2008) Rifaximin versus nonabsorbable disaccharides in the management of hepatic encephalopathy: a meta-analysis. Eur J Gastroenterol Hepatol 20: 1064-1070.

15. Bucci L, Palmieri GC (1993) Double-blind, double-dummy comparison between treatment with rifaximin and lactulose in patients with medium to severe degree hepatic encephalopathy. Curr Med Res Opin 13: 109-118

16. Poo JL, Gongora J, Sanchez-Avila F, Aguilar-Castillo S, Garcia-Ramos G et al. (2006) Efficacy of oral L-ornithine-L-aspartate in cirrhotic patients with hyperammonemic hepatic encephalopathy.Results of a randomized, lactulosecontrolled study. Ann Hepatol 5: 281-288.

17. Kircheis G, Nilius R, Held C, Berndt H, Buchner M, et al. (1997) Therapeutic efficacy of L-ornithine-L-aspartate infusions in patients with cirrhosis and hepatic encephalopathy: results of a placebo-controlled, double-blind study. Hepatology 25: 1351-1360

18. Schmid M, Peck-Radosavljevic M, Konig F, Mittermaier C, Gangl A et al. (2010) A double-blind,randomized,placebo-controlled trial of intravenous L-ornithineL-aspartate on postural control in patients with cirrhosis. Liver Int 30: 574-582.

19. Acharya SK, Bhatia V, Sreenivas V, Khanal S, Panda SK (2009) Efficacy of L-ornithine L-aspartate in acute liver failure: a double-blind, randomized, placebo-controlled study. Gastroenterology 36: 2159-2168.

20. Jiang Q, Jiang XH, Zheng MH, Chen YP (2009) L-Ornithine-l-aspartate in the management of hepatic encephalopathy: a meta-analysis. J Gastroentero Hepatol 24: 9-14

21. Ahmad I, Khan AA, Alam A, Dilshad A, Butt AK, et al. (2008) L-ornithine-L aspartate infusion efficacy in hepatic encephalopathy. J Coll Physicians Surg Pak 18: 684-687.

22. Stauch S, Kircheis G, Adler G, Beckh K, Ditschuneit H, et al. (1998) Ora L-ornithine-L-aspartate therapy of chronic hepatic encephalopathy: results of a placebo-controlled double-blind study. J Hepatol 28: 856-864.

23. Bass NM (2007) Review article: the current pharmacological therapies fo hepatic encephalopathy. Aliment Pharmacol Ther 25: 23-31.

24. Als-Nielsen B, Gluud LL, Gluud C (2004) Non-absorbable disaccharides fo hepatic encephalopathy: systematic review of randomised trials. BMJ 328 : 1046

25. Prasad S, Dhiman RK, Duseja A, Chawla YK, Sharma A, et al. (2007) Lactulose improves cognitive functions and health-related quality of life in patients with cirrhosis who have minimal hepatic encephalopathy. Hepatology 45: 549-559.

26. Als-Nielsen B, Gluud LL, Gluud C (2004) Benzodiazepine receptor antagonists for hepatic encephalopathy. Cochrane Database Syst Rev CD002798. 
Citation: Zheng MH, Sun DQ, Jiang Q, Shi KQ, Wu AM, et al. (2011) Pharmacotherapy for Hepatic encephalopathy: view of Evidence-Based Medicine. J Liver 1:102. doi:10.4172/2167-0889.1000102

Page 5 of 5

27. Ahboucha S, Araqi F, Layrargues GP, Butterworth RF (2005) Differential effects of ammonia on the benzodiazepine modulatory site on the GABA-A receptor complex of human brain. Neurochem Int 47: 58-63.

28. Ahboucha S, Butterworth RF (2004) Pathophysiology of hepatic encephalopathy: a new look at GABA from the molecular standpoint. Metab
Brain Dis 19: 331-343.

29. Goulenok C, Bernard B, Cadranel JF, Thabut D, Di Martino V, et al. (2002) Flumazenil vs. placebo in hepatic encephalopathy in patients with cirrhosis: a meta-analysis. Aliment Pharmacol Ther 16: 361-372. 